\title{
Correction to: Storage of blue carbon in isolated mangrove forests of the Galapagos' rocky coast
}

\author{
Matthew T. Costa $(\mathbb{D} \cdot$ Pelayo Salinas-de-León $(\mathbb{D}) \cdot$ Octavio Aburto-Oropeza $\mathbb{C}$
}

Published online: 26 August 2019

(C) Springer Nature B.V. 2019

Correction to: Wetlands Ecology and Management https://doi.org/10.1007/s11273-019-09653-8

In the original publication, the affiliation of second author and acknowledgements were incorrectly published. The correct affiliation and acknowledgements are given in this Correction.

Acknowledgements We are grateful for support from Scripps Institution of Oceanography, the Charles Darwin Foundation, and the Galapagos National Park. We especially thank SIO and CDF staff, especially E. Rastoin, for facilitating travel and field logistics; J. J. Cota-Nieto and I. Mascarenas for fieldwork; K.
Laface and E. Navarro for lab assistance; J. Kumagai for GIS support; and E. Cleland and J. Leichter for providing useful comments on the manuscript. This research was conducted under Galapagos National Park Directorate permit PC-16-15 granted to Dr. Pelayo Salinas de León from the Charles Darwin Foundation. Sediment samples were exported from Ecuador using the Ministerio del Ambiente permit 054-2015 DPNG. This is contribution number 2241 from the Charles Darwin Foundation for the Galapagos Islands. The data in this paper are available in the appendix.

The original article can be found online at https://doi.org/10.1007/s11273-019-09653-8.

M. T. Costa $(\bowtie) \cdot$ O. Aburto-Oropeza

Aburto-Oropeza Lab, Scripps Institution of

Oceanography, UCSD, 9500 Gilman Dr., La Jolla,

CA 92093-0206, USA

e-mail: mtcosta@ucsd.edu

P. Salinas-de-León

Charles Darwin Research Station, Charles Darwin

Foundation, Av. Charles Darwin, Puerto Ayora,

Galápagos, Ecuador

P. Salinas-de-León

Pristine Seas, National Geographic Society, 1145 17th St.

NW, Washington, DC 20036, USA 